\title{
One-year hemodynamic comparison of Perimount Magna with St Jude Epic aortic bioprostheses
}

Jerzy Bobiarski, Andrew E. Newcomb, Abdelsalam M. Elhenawy, Manjula Maganti, Joanne Bos, Suzanne Hemeon, Vivek Rao

Peter Munk Cardiac Centre, Toronto General Hospital, Toronto, Ontario, Canada

Submitted: 27 September 2011

Accepted: 11 March 2012

Arch Med Sci 2013; 9, 3: 445-451

DOI: $10.5114 /$ aoms.2013.35479

Copyright (c) 2013 Termedia \& Banach

\begin{abstract}
Introduction: Cardiac surgeons are using more bioprosthetic valves due to the ageing population as well as to improvements that have been made to these implants. We sought to compare the 1-year hemodynamics of two commercially available valves by echocardiographic parameters.

Material and methods: Retrospective review of our institutional database revealed 69 patients who received either Perimount Magna $(n=33)$ or St Jude Epic $(n=36)$ valves in the aortic position with no other valve surgery between June 2004 and March 2006. All patients received transthoracic echocardiography at 1 year. Comparisons between groups were made at baseline and at 1-year follow-up. In addition, a pairwise comparison was performed in each patient to determine the change in echocardiographic parameters between baseline and follow-up.

Results: Mean implanted valve size was similar (Magna $24.3 \pm 2.0 \mathrm{~mm}$ vs. Epic $24.1 \pm 2.2 \mathrm{~mm}$ ). Pre- and intraoperative patient variables were similar between the two groups. There were lower peak and mean pressure gradients in the Magna group, both at discharge and one year after surgery. This correlated with a larger indexed effective orifice area (Magna $0.8 \pm 0.2 \mathrm{~cm}^{2} / \mathrm{m}^{2} \mathrm{vs}$. Epic $0.67 \pm 0.2$ $\mathrm{cm}^{2} / \mathrm{m}^{2}, p=0.02$ ). In spite of these findings, left ventricular mass regression was not different.

Conclusions: These findings suggest that in a series with relatively low indexed effective orifice areas, the peak and mean gradients obtained were acceptable. More clinical follow-up of these patients is required to assess the true impact of prosthesis patient mismatch.
\end{abstract}

Key words: aortic valve replacement, echocardiography, outcomes.

\section{Introduction}

Biologic stented valves are being utilized more frequently due to an ageing population, the improving long-term outcomes, and the ease of implantability compared with stentless valves. These valves have had continuous improvements made, including relocation of the valve apparatus to a supra-annular location, and various anti-calcification treatments.

In comparison to normal native valves, all stented biological prostheses are relatively obstructive. Therefore, the valve manufacturing companies had to overcome the challenge of creating a valve with maximal hemodynamic performance to avoid prosthesis-patient mismatch and to result in optimal left ventricular mass regression (LVMR) after valve replacement. The Carpentier-Edwards Perimount Magna ${ }^{\text {TM }}$ (Magna) aor-

\author{
Corresponding author: \\ Jerzy Bobiarski PhD \\ Peter Munk Cardiac Centre \\ Toronto General Hospital \\ 30 Bond Street \\ M5G 2C4 Toronto (ON) \\ Canada \\ Phone: +14168312169 \\ E-mail: boberro@yahoo.com
}


tic pericardial valve (Edwards Lifesciences, Irvine, CA), introduced in 2002, is a modification of the Carpentier-Edwards Perimount standard aortic bioprosthesis that has been used since 1981 and has excellent long-term clinical and hemodynamic results [1].

To achieve improved hemodynamic performance, the Magna valve was designed with a smaller sewing ring [2], and the sewing cuff was displaced so that both sewing cuff and leaflets remain in a supra-annular position. This valve incorporates a proprietary anti-calcification treatment called ThermaFix $^{\top \mathrm{M}}$. This includes tissue preservation with glutaraldehyde, followed by heat treatment to remove any unstable bonds between glutaraldehyde and lysine side chains of the collagen. This is followed by the use of alcohol and surfactant to remove any phospholipids within the leaflet structure. They are available in odd millimeter sizes from $19 \mathrm{~mm}$ to $29 \mathrm{~mm}$, and are mounted on a cobaltchromium wire and polyester frame.

The St Jude Medical (SJM) Epic ${ }^{T M}$ (St Jude Medical Inc, St Paul, MN) Porcine Bioprosthetic heart valve (Epic) is manufactured from selected sizematched porcine aortic valve cusps. Tissue fixation is achieved with a glutaraldehyde solution. This valve is morphologically identical to the previous generation SJM Biocor ${ }^{T M}$ valve that has been implanted since 1981. Anti-calcification treatment has been incorporated into this valve with the addition of a $95 \%$ ethanol solution. For the aortic position, this valve is available in odd millimeter sizes from $21 \mathrm{~mm}$ to $29 \mathrm{~mm}$. The valves are mounted on a flexible acetyl copolymer stent with a low profile design and scalloped shape that permits supraannular placement of the bioprosthesis.

There has been a great deal of information about the longer-term clinical outcomes for the predecessors of these valves [1, 3-5], but we were interested to see what the short-term hemodynamics were, and if this had any influence on early ventricular remodeling.

The aim of this study was therefore to compare early postoperative hemodynamic performance of the Magna pericardial and Epic porcine bioprosthesis in the aortic position.

\section{Material and methods}

We retrospectively reviewed all perioperative data entered prospectively into our institutional database from June 2004 to March 2006. A group of 69 consecutive patients was identified who underwent aortic valve replacement (AVR) with either the Magna $(n=33)$ or the Epic $(n=36)$ bioprosthesis, with or without concomitant procedures. Patients receiving multiple valve replacements were excluded to reduce bias in echo and clinical interpretation of the data. Ethical approval was granted by our Institutional Research Ethics Board and the need for individual patient consent was waived.

\section{Operative technique}

Operations were performed using general anesthesia via full median sternotomy using standard cardiopulmonary bypass techniques with mild systemic hypothermia. A transverse aortotomy was performed $1 \mathrm{~cm}$ to $2 \mathrm{~cm}$ above the right coronary ostium. Cardioplegic arrest was achieved and maintained with cold blood delivered in an antegrade fashion with or without retrograde delivery and was dependent on surgeon preference. The choice of Magna or Epic valve was determined by a combination of surgeon and patient preference. After the native aortic valve was excised, the annulus was measured with the appropriate sizer for the chosen prosthesis. The prosthesis size that would comfortably fit within the aortic annulus was chosen. To avoid prosthesis-patient mismatch, annular enlargement with bovine or autologous pericardium [6] was performed to achieve a minimum projected indexed effective orifice area of $0.75 \mathrm{~cm}^{2}$ when the attending surgeon believed the risk was justified. The valves were implanted in the supraannular position using pledgeted 2-0 braided polyester mattress sutures in a non-everting fashion. In patients requiring concomitant procedures such as coronary bypass grafting or septal myectomy, the appropriate surgical treatment was performed before AVR. Patients with marked ascending aorta dilatation received a supracoronary Dacron tube graft $(n=4)$.

\section{Postoperative follow-up}

To assess postoperative hemodynamic performance, transthoracic echocardiography was performed prior to discharge from hospital and then 1 year postoperatively. American Society of Echocardiography guidelines [7] dictated our echocardiographic assessment. Pulsed-wave Doppler was used to measure the peak and mean blood flow velocities in the left ventricular outflow tract (LVOT) and then transvalvular pressure gradients were obtained using the modified Bernoulli equation: Peak gradient $(\mathrm{mm} \mathrm{Hg})=4 \times\left(\mathrm{V}_{\mathrm{AV} \max ^{2}}-\mathrm{V}_{\mathrm{LVOT} m a x}{ }^{2}\right)$. Mean gradient $(\mathrm{mm} \mathrm{Hg})=4 \times\left(\mathrm{V}_{\mathrm{AVmean}}{ }^{2}-\mathrm{V}_{\text {LVOTmean }}{ }^{2}\right)$, where $\mathrm{V}_{\mathrm{AV}}$ is the transaortic velocity (meters per second) and $\mathrm{V}_{\mathrm{LVOT}}$ is the subaortic LVOT peak or mean velocity (meters per second). Effective orifice area (EOA) in $\mathrm{cm}^{2}$ was calculated by the continuity equation $\left(E O A=\left(C A_{L V O T}-T_{V I} I_{L V O T}\right) / T V I_{A V}\right)$, where $C S A_{L V O T}=$ LVOT cross sectional area $\left(\pi \mathrm{r}^{2} / 4\right)$ in $\mathrm{cm}^{2}$, $\mathrm{TVI}_{\text {LVOT }}=$ LVOT time velocity integral of forward blood flow in $\mathrm{cm}$, TVIAV is the transvalvular time velocity integral of blood flow in $\mathrm{cm}$. The EOA was then indexed to body surface area to assess the pres- 
ence of patient-prosthesis mismatch (PPM) (defined as < 0.75) [8]. The LV mass was calculated with the corrected American Society of Echocardiography (ASE) formula, and indexed to body surface area [9].

\section{Statistical analysis}

All statistical analyses were conducted with SAS Version 9.1 software for Windows (SAS Institute, Inc, Cary, NC). Categorical variables were analyzed by using $\chi^{2}$ or Fisher's exact test (as appropriate) and are expressed as percentages. Continuous variables are expressed as means \pm standard deviation and were compared with the Student $t$ test or the Wilcoxon rank-sum test. To compare the echo outcomes of continuous variables at 1 week and 1 year within each valve type, longitudinal analysis was conducted by repeated measures analysis of variance.

\section{Results}

There were 69 patients with aortic valve replacement included in this analysis. The mean implanted labeled valve size (Magna $24.3 \pm 2.0 \mathrm{~mm}$ vs. Epic $24.1 \pm 2.2 \mathrm{~mm}$ ) was not different between the groups $(p=0.51)$. Valves of all sizes for both types were implanted as appropriate. Preoperative patient characteristics were comparable in the two groups and are summarized in Table I. Although aortic stenosis was the main indication for surgery in both groups, the prevalence of senile calcific degeneration of the valve was higher in the Epic group, while the incidence of bicuspid aortic valve disease was significantly higher in the Magna group. Intraoperative variables were similar for the two groups and are summarized in Table II. There was a higher incidence of aortic root enlargement performed in the Magna group. This difference was surgeon dependent and may represent the increased size of the patients in that group.

Early postoperative outcomes are presented in Table III. The incidence of early pulmonary complications and myocardial infarction was higher in the Epic group. There were no in-hospital or 30-day deaths in this cohort.

Transthoracic echocardiograms were performed before discharge and 1 year after surgery in all patients. These early postoperative and 1-year hemodynamic measurements are listed in Table IV. A summary of the mean and peak gradients early and at 1 year according to valve size is provided in Table $V$. The Magna patients had a larger effective orifice area indexed to body surface area (iEOA), both early postoperatively and after 1 year. They also demonstrated lower peak and mean transvalvular gradients at both time periods (Figure 1). This did not translate into a benefit of left ventric-
Table I. Preoperative variables for Magna versus Epic aortic bioprostheses

\begin{tabular}{|c|c|c|c|}
\hline Variable & $\begin{array}{l}\text { Magna } \\
(n=33)\end{array}$ & $\begin{array}{c}\text { Epic } \\
(n=36)\end{array}$ & Value of $p$ \\
\hline Age [years] & $70.6 \pm 8.2$ & $73.5 \pm 6.5$ & 0.1 \\
\hline Body surface area $\left[\mathrm{m}^{2}\right]$ & $1.94 \pm 0.23$ & $1.90 \pm 0.24$ & 0.5 \\
\hline Male sex & 23 & 23 & 0.6 \\
\hline LVEF $<0.40$ & 6 & 6 & 0.9 \\
\hline NYHA class III or IV & 21 & 28 & 0.2 \\
\hline Reoperation (CABG) & 0 & 2 & 0.2 \\
\hline Reoperation (AVR) & 0 & 1 & 0.3 \\
\hline Angina & 12 & 21 & 0.07 \\
\hline Left main disease & 0 & 2 & 0.2 \\
\hline Preoperative MI & 3 & 2 & 0.6 \\
\hline Smoking & 19 & 23 & 0.6 \\
\hline Stroke/TIA & 4 & 5 & 0.8 \\
\hline COPD & 0 & 2 & 0.2 \\
\hline $\mathrm{CHF}$ & 6 & 12 & 0.15 \\
\hline Hypertension & 21 & 24 & 0.8 \\
\hline AF & 3 & 0 & 0.07 \\
\hline Hyperlipidemia & 16 & 31 & 0.0009 \\
\hline Renal failure & 0 & 0 & \\
\hline Diabetes mellitus & 6 & 14 & 0.06 \\
\hline PVD & 5 & 14 & 0.03 \\
\hline Family history of CAD & 19 & 17 & 0.4 \\
\hline $\begin{array}{l}\text { Operation required on } \\
\text { same day as hospitalizati }\end{array}$ & tion & 8 & 0.9 \\
\hline Endocarditis & 0 & 0 & \\
\hline Aortic valve pathology & & & 0.4 \\
\hline Stenosis & 27 & 33 & \\
\hline Insufficiency & 4 & 1 & \\
\hline Mixed & 2 & 2 & \\
\hline Aortic valve etiology & & & 0.2 \\
\hline Calcific degeneration & 14 & 29 & \\
\hline Bicuspid & 16 & 4 & \\
\hline Rheumatic & 1 & 0 & \\
\hline Annuloaortic ectasia & 1 & 0 & \\
\hline Prosthetic dysfunction & 0 & 1 & \\
\hline Other & 1 & 2 & \\
\hline
\end{tabular}

NYHA - New York Heart Association, LVEF - left ventricular ejection fraction, $C A B G$ - coronary artery bypass graft surgery, AVR - aortic valve replacement, $M I$ - myocardial infarction, TIA - transient ischemic attack, $C O P D$ - chronic obstructive pulmonary disease, CHF - congestive heart failure, $A F$ - atrial fibrillation, $P V D$ - peripheral vascular disease, $C A D$ - coronary artery disease

ular mass regression, as the mean left ventricular mass regression was not different between groups at 1 year (Figure 2). 
Table II. Intraoperative variables for Magna versus Epic aortic bioprostheses

\begin{tabular}{|c|c|c|c|}
\hline Variable & $\begin{array}{l}\text { Magna } \\
(n=33)\end{array}$ & $\begin{array}{c}\text { Epic } \\
(n=36)\end{array}$ & Value of $p$ \\
\hline Aortic root enlargement & 14 & 8 & 0.07 \\
\hline CABG & 19 & 25 & 0.3 \\
\hline $\begin{array}{l}\text { Replacement ascending } \\
\text { aorta }\end{array}$ & g & 2 & 0.9 \\
\hline Septal myectomy & 3 & 3 & 0.9 \\
\hline $\begin{array}{l}\text { Aortic cross-clamp } \\
\text { time }[\mathrm{min}]\end{array}$ & $94.5 \pm 25.4$ & $94.4 \pm 27.2$ & 0.5 \\
\hline CPB time [min] & $114.0 \pm 27.6$ & $116.8 \pm 34.6$ & 0.5 \\
\hline
\end{tabular}

$C A B G$ - coronary artery bypass graft surgery, $C P B$ - cardiopulmonary bypass
Table III. Early postoperative outcomes for Magna versus Epic aortic bioprostheses

\begin{tabular}{|lccc|}
\hline Variable & $\begin{array}{c}\text { Magna } \\
(n=33)\end{array}$ & $\begin{array}{c}\text { Epic } \\
(n=36)\end{array}$ & Value of $p$ \\
\hline Reexploration for bleeding & 3 & 3 & 0.9 \\
\hline Mean ICU stay [h] & 51.5 & 64.02 & 0.4 \\
\hline Mean ventilation [h] & 14.5 & 20.6 & 0.2 \\
\hline Mean hospital stay [days] & 7.9 & 9.4 & 0.09 \\
\hline Sternal wound infection & 0 & 1 & 0.3 \\
\hline Pulmonary complications & 3 & 4 & 0.8 \\
\hline Myocardial infarction & 0 & 1 & 0.3 \\
\hline Renal failure & 0 & 0 & \\
\hline Stroke & 0 & 0 & \\
\hline Mortality & 0 & 0 & \\
\hline
\end{tabular}

ICU - intensive care unit

Table IV. Echocardiographic comparison of Magna and Epic aortic hemodynamic performances and left ventricular measurements 1 week and 1 year postoperatively

\begin{tabular}{|lcccccccc|}
\hline Variable & \multicolumn{2}{c}{ One week postoperatively } & \multicolumn{2}{c|}{ One year postoperatively } & \multicolumn{2}{c|}{ Differences over time } \\
\cline { 2 - 10 } & $\begin{array}{c}\text { Magna } \\
(n=33)\end{array}$ & $\begin{array}{c}\text { Epic } \\
(n=36)\end{array}$ & Value of $p$ & $\begin{array}{c}\text { Magna } \\
(n=29)\end{array}$ & $\begin{array}{c}\text { Epic } \\
(n=34)\end{array}$ & Value of $p$ & $\begin{array}{c}\text { Magna } \\
\text { Value of } p\end{array}$ & $\begin{array}{c}\text { Epic } \\
\text { Value of } p\end{array}$ \\
\hline Aortic valve area [cm²] & $1.35 \pm 0.27$ & $1.23 \pm 0.28$ & 0.05 & $1.55 \pm 0.36$ & $1.28 \pm 0.35$ & 0.003 & 0.02 & 0.56 \\
\hline iEOA [cm²/m²] & $0.70 \pm 0.15$ & $0.66 \pm 0.17$ & 0.22 & $0.8 \pm 0.2$ & $0.67 \pm 0.2$ & 0.02 & 0.04 & 0.73 \\
\hline Peak gradient [mm Hg] & $21.7 \pm 7.8$ & $29.0 \pm 11.3$ & 0.004 & $20.34 \pm 5.4$ & $30.6 \pm 12.5$ & $<0.0001$ & 0.4 & 0.59 \\
\hline Mean gradient [mm Hg] & $10.2 \pm 4.2$ & $14.1 \pm 5.5$ & 0.002 & $10.4 \pm 2.7$ & $15.3 \pm 6.5$ & 0.0002 & 0.8 & 0.4 \\
\hline LVEDD [mm] & $45.4 \pm 6.5$ & $44.4 \pm 8.2$ & 0.25 & $45.9 \pm 5.7$ & $44.8 \pm 4.9$ & 0.4 & 0.7 & 0.8 \\
\hline LVESD [mm] & $31.7 \pm 7.0$ & $30.6 \pm 9.3$ & 0.15 & $27.7 \pm 6.4$ & $27.2 \pm 5.5$ & 0.9 & 0.03 & 0.07 \\
\hline LVMI [mm/m²] & $105.4 \pm 27.7$ & $203.7 \pm 74.1$ & $<0.0001$ & $102.1 \pm 31.2$ & $196.1 \pm 42.5$ & $<0.0001$ & 0.7 & 0.6 \\
\hline LVMR & & & $-6.8 \pm 26.9$ & $-10.4 \pm 52.8$ & 0.57 & \\
\hline
\end{tabular}

iEOA - indexed effective orifice area, LVEDD - left ventricular end diastolic dimension, LVESD - left ventricular end systolic dimension, $L V M I$ - left ventricular mass index, LVMR - left ventricular mass regression

Table V. Gradients according to brand and size

\begin{tabular}{|c|c|c|c|c|c|c|c|c|c|c|c|c|}
\hline \multirow[t]{2}{*}{ Variable } & \multicolumn{6}{|c|}{ Early - 1 week } & \multicolumn{6}{|c|}{1 Year } \\
\hline & $19 \mathrm{~mm}$ & $21 \mathrm{~mm}$ & $23 \mathrm{~mm}$ & $25 \mathrm{~mm}$ & $27 \mathrm{~mm}$ & $29 \mathrm{~mm}$ & $19 \mathrm{~mm}$ & $21 \mathrm{~mm}$ & $23 \mathrm{~mm}$ & $25 \mathrm{~mm}$ & $27 \mathrm{~mm}$ & $29 \mathrm{~mm}$ \\
\hline Epic numbers & 0 & 9 & 9 & 14 & 6 & 1 & 0 & 7 & 9 & 13 & 6 & 1 \\
\hline Epic mean gradient & & $\begin{array}{l}16.4 \\
\pm 6.4\end{array}$ & $\begin{array}{r}13.1 \\
\pm 2.9\end{array}$ & $\begin{array}{l}14.9 \\
\pm 6.1\end{array}$ & $\begin{array}{l}10.8 \\
\pm 2.9\end{array}$ & 7.0 & N/A & $\begin{array}{l}18.5 \\
\pm 7.7\end{array}$ & $\begin{array}{l}16.4 \\
\pm 6.1\end{array}$ & $\begin{array}{r}13.1 \\
\pm 4.6\end{array}$ & $\begin{array}{l}16.5 \\
\pm 8.3\end{array}$ & 7.0 \\
\hline Epic peak gradient & & $\begin{array}{c}33.5 \\
\pm 13.2\end{array}$ & $\begin{array}{l}29.2 \\
\pm 6.7\end{array}$ & $\begin{array}{r}29.8 \\
\pm 12.4\end{array}$ & $\begin{array}{l}21.6 \\
\pm 4.1\end{array}$ & 13.0 & N/A & $\begin{array}{c}35.1 \\
\pm 14.4\end{array}$ & $\begin{array}{c}33.1 \\
\pm 12.9\end{array}$ & $\begin{array}{l}26.8 \\
\pm 9.0\end{array}$ & $\begin{array}{r}33.3 \\
\pm 15.6\end{array}$ & 12.96 \\
\hline Magna numbers & 1 & 2 & 10 & 14 & 5 & 1 & 1 & 1 & 9 & 13 & 5 & 1 \\
\hline $\begin{array}{l}\text { Magna mean } \\
\text { gradient }\end{array}$ & 10.0 & $\begin{array}{l}10.5 \\
\pm 6.4\end{array}$ & $\begin{array}{l}12.0 \\
\pm 4.0\end{array}$ & $\begin{array}{c}10.1 \\
\pm 4.3^{\star}\end{array}$ & $\begin{array}{c}6.8 \\
\pm 2.7^{\star}\end{array}$ & 5.8 & 14.0 & 13.0 & $\begin{array}{c}10.1 \\
\pm 1.7^{\star}\end{array}$ & $\begin{array}{r}11.0 \\
\pm 3.0\end{array}$ & $\begin{array}{c}7.8 \\
\pm 2.3\end{array}$ & 8.7 \\
\hline $\begin{array}{l}\text { Magna peak } \\
\text { gradient }\end{array}$ & 21.2 & $\begin{array}{r}25.6 \\
\pm 11.3\end{array}$ & $\begin{array}{l}23.9 \\
\pm 5.3\end{array}$ & $\begin{array}{l}21.6 \\
\pm 9.7\end{array}$ & $\begin{array}{c}15.9 \\
\pm 3.8^{\star}\end{array}$ & 13.0 & 33.6 & 25.0 & $\begin{array}{r}20.9 \\
\pm 3.6^{\star}\end{array}$ & $\begin{array}{r}20.9 \\
\pm 5.0\end{array}$ & $\begin{array}{c}14.6 \\
\pm 3.5^{\star}\end{array}$ & 16.0 \\
\hline
\end{tabular}

All measures are listed as mean \pm standard deviation. Units are in $\mathrm{mm} \mathrm{Hg} .{ }^{*}$ Significant $(p<0.05)$ compared with Epic 

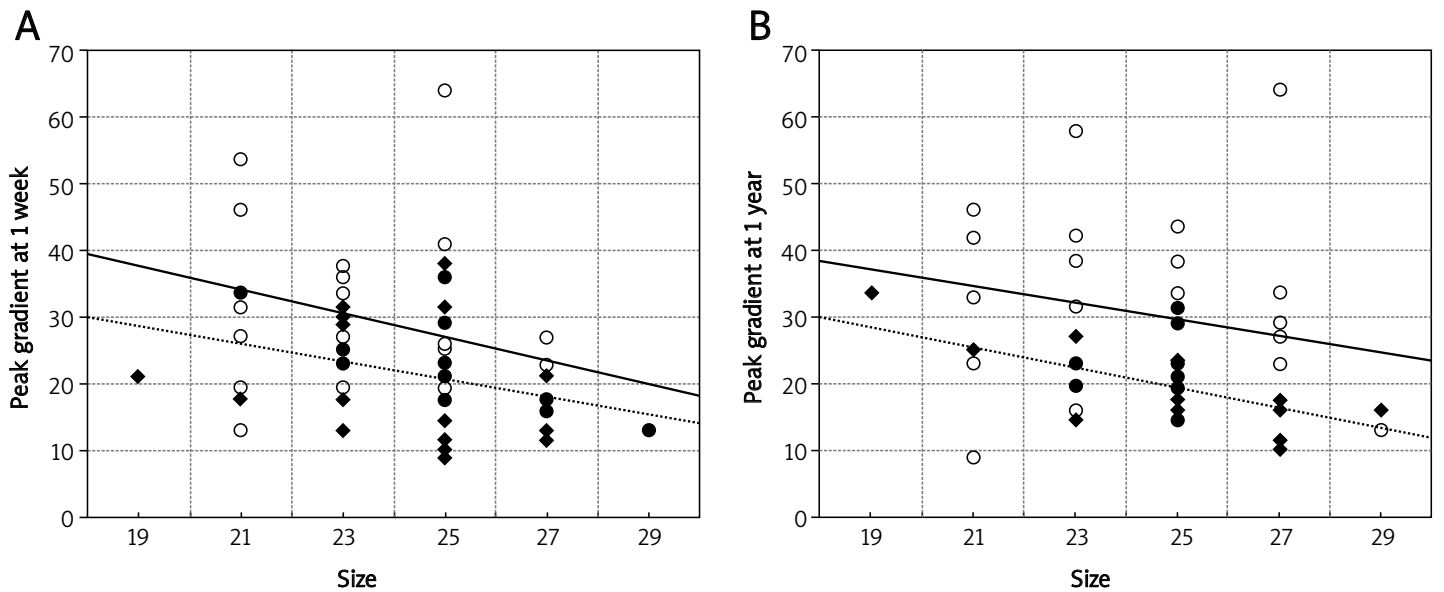

C

D
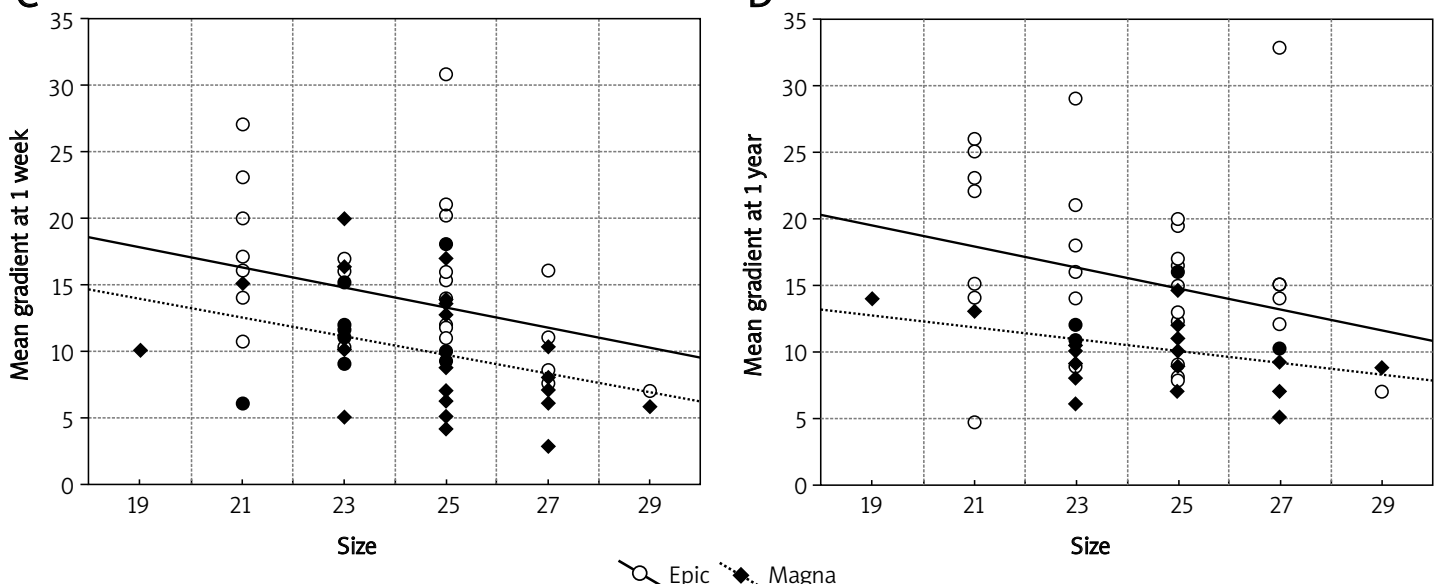

Figure 1. Comparisons of the peak (A, B) and mean (C, D) bioprosthetic valve gradients at 1 week and 1 year. These are categorized by brand and labeled size

\section{Discussion}

When implanting a prosthetic heart valve, the primary goal is to insert the largest prosthesis that will optimize the effective orifice area for the patient, thus minimizing the transvalvular pressure gradient [8]. The rationale for this is to prevent left ventricular diastolic dysfunction and to promote regression of left ventricular hypertrophy $[10,11]$.

The main aim of the present study was to compare the early and 1-year echocardiographic hemodynamic performance of a relatively new Epic valve, with that of the Perimount Magna valve by transthoracic echocardiography.

Our study showed significantly lower transvalvular gradients for patients receiving Magna valves compared with patients receiving similar sized Epic valves. The transvalvular gradient is dependent on flow and EOA, with the EOA related to the internal diameter of the implanted prosthesis. The supra-annular position of prostheses is commonly undertaken when implanting stented tissue valves to maximize the implanted size within a defined tissue annulus dimension [12]. Stent- ed valves all have a tendency to create higher transvalvular gradients due to obstruction by sewing ring and stents, as well as potentially suboptimal leaflet opening. According to Gerosa and colleagues, who measured the geometric dimensions of five different supra-annular prostheses, comparison between different tissue valves is complicated and sometimes misleading because of the discrepancies between the manufacturer's branded sizing, and the actual internal and external diameters of the respective valves [13]. This makes it imperative to obtain accurate and clinically relevant data on the hemodynamics and patient outcomes to compare the performances of the valves.

The iEOA has been taken as a parameter that standardizes the effect of prosthesis size through its relation to body surface area. Although the effect of indexed EOA on patient survival after AVR remains controversial, iEOA values lower than 0.6 to 0.65 have been linked with poorer long-term survival and hemodynamic outcomes [14]. In our group, the Magna patients had a larger indexed effective orifice area at both times, and this improved over 

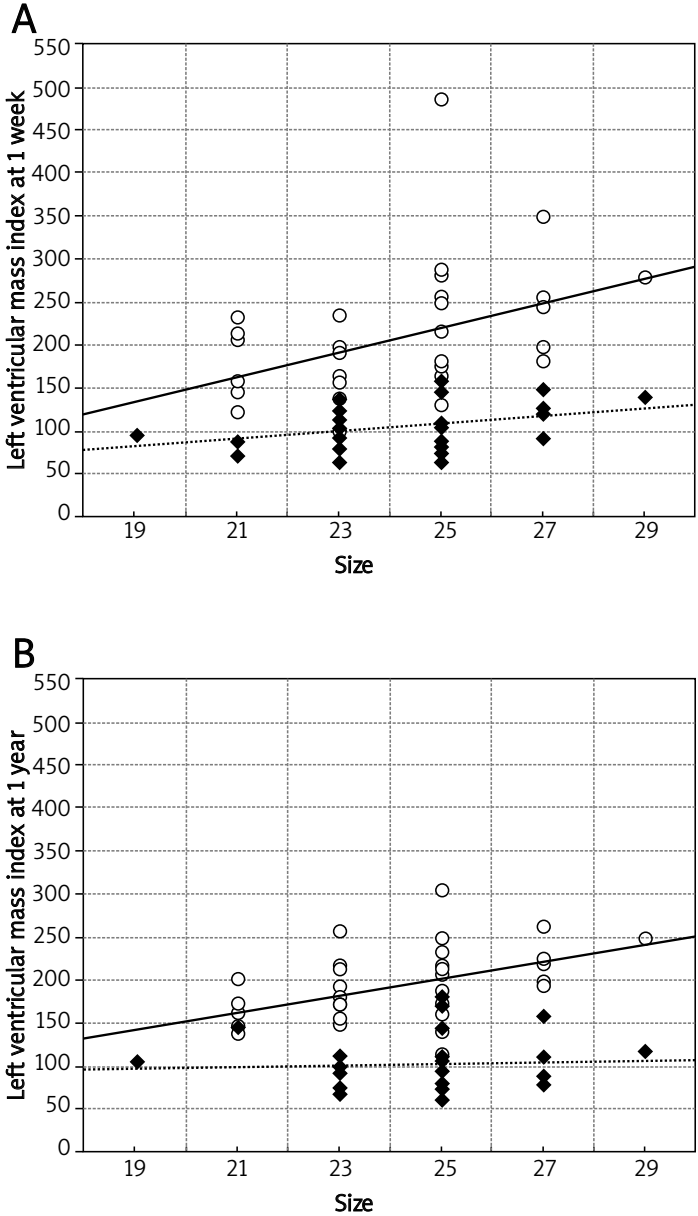

C

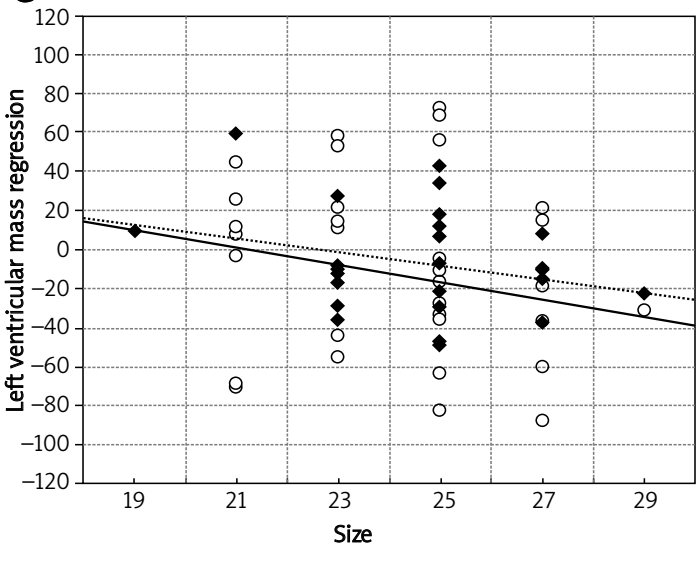

○ Epic $*$ Magna

Figure 2. Comparisons of the LVMI at 1 week $(\mathrm{A})$ and 1 year (B). Also comparison of the LVMR after 1 year (C). These are categorized by brand and labeled size

time. The iEOA parameters in the Epic cohort remained low up to 1 year of follow-up with a mean value of 0.66 . This prosthesis-patient mismatch may result in persistent left ventricular outflow tract obstruction and higher postoperative transvalvular gradients. This residual obstruction may prevent the regression of left ventricular mass observed in most patients undergoing AVR for aortic stenosis [14]. This regression of concentric hypertrophy plays an important role in the beneficial process of remodeling of the myocardium. In our study, LVMR was noticeable in all patients, with no significant differences between groups despite the different gradients for the two groups. The report of Christakis et al. [15] suggests that LVMR occurs predominantly in the first 6 months following surgery and appears to plateau thereafter. Therefore longer follow-up is unlikely to result in further potential differences in LVMR for these patients.

This paper demonstrates better early and 1-year gradients across the Perimount Magna valves compared with the corresponding SJM Epic valves. In spite of these echo data suggesting superiority of one valve over the other, there are no apparent clinical differences in terms of LVMR or death. A surprising finding of the study relates to the EOA data, which appear to show a different population to that seen elsewhere. The mean iEOA for the Epic valves was 0.67 and from the Magna valve was 0.8. There was a range of valve sizes and the average for each was $24.1 \pm 2.2 \mathrm{~mm}$ and $24.3 \pm 2.0 \mathrm{~mm}$ respectively. These EOA data for the Magna valve are comparable with other authors, as are the gradients obtained [14]. Although the better hemodynamic performance of the Magna valve still remains a strong argument in favor of this bioprosthesis, long-term clinical outcomes need to be additionally evaluated to confirm its superiority and benefits for the patients.

In conclusion, this paper retrospectively analyzed patients undergoing aortic valve replacement surgery using either the St Jude Medical Epic porcine, or the Carpentier Edwards Perimount Magna bovine pericardial bioprosthesis, both of which offer improvements on previous versions so one should expect excellent long-term performance. These patients were followed with echo at 1 year, and while there were differences in EOA and gradients, there was no difference in clinically important left ventricular mass regression between the groups. This may suggest that it may be more relevant to evaluate and report on left ventricular mass regression as a quality parameter of the various valve replacements available rather than relying on gradients per se.

This study is limited by the fact that is it is retrospective in nature and reflects the experience of a single institution. The sample size may not be large enough to detect differences in the outcomes we measured, leading to an $\alpha$ error. There were a number of surgeons implanting bioprostheses during this time period, therefore leading to variations in sizing and concomitant procedures. 


\section{References}

1. Banbury MK, Cosgrove DM, Thomas JD, et al. Hemodynamic stability during 17 years of the CarpentierEdwards aortic pericardial bioprosthesis. Ann Thorac Surg 2002; 73: 1460-5.

2. Botzenhardt F, Eichinger WB, Bleiziffer S, et al. Hemodynamic comparison of bioprotheses for complete supraannular position in patients with small aortic annulus. JACC 2005; 45: 2054-60.

3. Badiu CC, Bleiziffer S, Eichinger WB, et al. Long-term performance of the Hancock bioprosthetic valved conduit in the aortic root position. J Heart Valve Dis 2011; 20: 191-8.

4. Eichinger W, Gunzinger R, Botzenhardt F, Simmerl D, Gansera B, Kemkes BM. The Mosaic bioprosthesis in the aortic position at five years. J Heart Valve Dis 2000; 9 : 653-60.

5. Dellgren G, David TE, Raanani E, Armstrong S, Ivanov J, Rakowski H. Late hemodynamic and clinical outcomes of aortic valve replacement with the Carpentier-Edwards Perimount pericardial bioprosthesis. I Thorac Cardiovasc Surg 2002; 124: 146-54.

6. Peterson MD, Borger MA, Feindel CM, David TE. Aortic annular enlargement during aortic valve replacement: improving results with time. Ann Thorac Surg 2007; 83: 2044-9.

7. Zoghbi WA, Chambers JB, Dumesnil JG, et al.; American Society of Echocardiography's Guidelines and Standards Committee; Task Force on Prosthetic Valves; American College of Cardiology Cardiovascular Imaging Committee; Cardiac Imaging Committee of the American Heart Association; European Association of Echocardiography; European Society of Cardiology; Japanese Society of Echocardiography; Canadian Society of Echocardiography; American College of Cardiology Foundation; American Heart Association; European Association of Echocardiography; European Society of Cardiology; Japanese Society of Echocardiography; Canadian Society of Echocardiography. Recommendations for evaluation of prosthetic valves with echocardiography and doppler ultrasound: a report From the American Society of Echocardiography's Guidelines and Standards Committee and the Task Force on Prosthetic Valves, developed in conjunction with the American College of Cardiology Cardiovascular Imaging Committee, Cardiac Imaging Committee of the American Heart Association, the European Association of Echocardiography, a registered branch of the European Society of Cardiology, the Japanese Society of Echocardiography and the Canadian Society of Echocardiography, endorsed by the American College of Cardiology Foundation, American Heart Association, European Association of Echocardiography, a registered branch of the European Society of Cardiology, the Japanese Society of Echocardiography, and Canadian Society of Echocardiography. J Am Soc Echocardiogr 2009; 22: 975-1014.

8. Rao V, Jamieson WR, Ivanov J, et al. Prosthesis-patient mismatch affects survival after aortic valve replacement. Circulation 2000; 102: III5-9.

9. Lang RM, Bierig M, Devereux RB, et al.; American Society of Echocardiography's Nomenclature and Standards Committee; Task Force on Chamber Quantification; American College of Cardiology Echocardiography Committee; American Heart Association; European Association of Echocardiography, European Society of Cardiology. Recommendations for chamber quantification. Eur J Echocardiogr 2006; 7: 79-108.
10. Pibarot P, Dumesnil JG, Lemieux M, Cartier P, Metras J, Durand LG. Impact of prosthesis-patient mismatch on hemodynamic and symptomatic status, morbidity and mortality after aortic valve replacement with a bioprosthetic heart valve. J Heart Valve Dis 1998; 7: 211-8.

11. Gonzalez-Juanatey JR, Garcia-Acuna JM, Vega Fernandez $M$, et al. Influence of the size of aortic valve prostheses on hemodynamics and change in left ventricular mass: implications for the surgical management of aortic stenosis. J Thorac Cardiovasc Surg 1996; 112: 273-80.

12. Sievers HH. Prosthetic aortic valve replacement. J Thorac Cardiovasc Surg 2005; 129: 961-5.

13. Gerosa G, Tarzia V, Rizzoli G, Bottio T. Small aortic annulus: the hydrodynamic performances of 5 commercially available tissue valves. J Thorac Cardiovasc Surg 2006; 131: 1058-64.

14. Tasca G, Brunelli F, Cirillo M, et al. Impact of valve prosthesis-patient mismatch on left ventricular mass regression following aortic valve replacement. Ann Thorac Surg 2005; 79: 505-10.

15. Christakis GT, Joyner CD, Morgan CD, et al. Left ventricular mass regression early after aortic valve replacement. Ann Thorac Surg 1996; 62: 1084-9. 